\title{
La relevancia de las pymes en la política industrial de Indonesia
}

\section{Introducción}

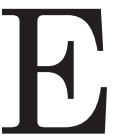
n las últimas dos décadas se ha enfocado el crecimiento económico de los países en desarrollo a través de sus pequeñas y medianas empresas (pymes), así se puede observar en la asignación de fondos públicos de las regiones del mundo. Es el caso del Banco Mundial, así como del Banco de Desarrollo de Asia; instituciones que han sugerido repetidamente el crecimiento de varias secciones de organizaciones en las diferentes economías, con el fin de alcanzar mejor generación de empleo, distribución del ingreso, progreso rural y erradicación de la pobreza, básicamente (Hooley y Muzaffer, 2003).

Por ello, en Indonesia la problemática de la política industrial se puede rescatar a través de la atención a las pymes, las cuales demandan una conducción interdisciplinaria para destacar en el entorno competitivo internacional, que considere desde la administración y la economía, hasta la sociedad y la política, que oriente programas y acciones para el fomento y desarrollo de estas entidades productivas, ya que se presentan en una de las etapas iniciales de desarrollo industrial.

En este artículo se analiza el papel que han jugado las pymes en la política industrial de Indonesia, a través de tres

* Profesora-Investigadora del Departamento de Estudios del Pacífico, cucsh-Universidad de Guadalajara.

\section{MÉXICO YLACUENCADEL PACÍFICO \\ vol. 10, núm. 29 / mayo - agosto de 2007}

apartados. En la primera parte se hace una revisión de las cuatro etapas de la política industrial de aquel país, desde 1966 hasta 2005; en la segunda parte se identifican los principales errores cometidos en la conducción de la política industrial, en los que la falta de desarrollo de las pymes participa de manera significativa; y en la tercera parte, se hace énfasis en la relevancia que precisamente tienen las pymes en la política industrial.

\section{Revisión de la política industrial de Indonesia}

La política industrial de Indonesia se puede dividir en cuatro etapas: 1966-1974, 1975-1984, 1985-1997, 1998-2005 (Kim, 2005). La primera etapa (1966-1974) se caracterizó por su estrategia económica de "puerta abierta", llamada así por tener el objetivo de atraer el capital extranjero para sostener la carga de la deuda y la problemática económica que el gobierno de Suharto heredó de su predecesor. Esta estrategia de "puerta abierta" atrajo exitosamente la inversión extranjera ubicada principalmente en recursos naturales y préstamos para financiar importaciones y rehabilitar infraestructura.

La segunda etapa (1975-1984) se desarrolló en el periodo del boom del petróleo, cuando la política de sustitución de importaciones se mantuvo con el ingreso obtenido del alto precio del petróleo, cuyos 
recursos sirvieron para financiar a sectores como el acero, el gas natural, aceites refinados y aluminio. De esta manera, el gobierno pretendió establecer una política industrial basada en la industria pesada y en proyectos de los recursos naturales.

La tercera etapa (1985-1997) estuvo marcada por un cambio dramático, debido al colapso de los precios del petróleo, que llevó a los políticos a regresar a la estrategia de "puerta abierta" respecto de la política de comercio e inversión extranjera. No obstante, a partir de 1985, el ambiente económico internacional fue benéfico para Indonesia porque siguió una re-valuación de la moneda en la que se reestructuraron las industrias manufactureras de la región. Es el caso de las compañías japonesas de artículos electrónicos y de automóviles, que empezaron a reubicar sus empresas en los países del sureste asiático. Asimismo, a fines de los años ochenta, continuó una significativa inversión en industrias intensivas en mano de obra, como vestido y calzado, con empresas de Corea del Sur, Taiwan, Hong Kong y Singapur (Falck, 1998).

El ingreso de la inversión extranjera y la sustancial inversión local marcaron las características de la actividad industrial de este periodo. En esa etapa, a pesar de la inminente liberalización del comercio, el proteccionismo proliferó en diversas industrias a través de la aplicación de tarifas. De tal manera que una larga lista de productos se mantuvieron protegidos frente a la inversión extranjera y algunas áreas fueron protegidas por el gobierno como empresas del Estado, entre ellas se identifica el ensamblaje de automóviles, fabricación de cemento y acero, ingeniería pesada, fabricación de metal y productos farmacéuticos (Kim, 2005).

Esta protección ha sido calificada como poco exitosa para dichas industrias, debido a que éstas no aportaron una contribución industrial significativa y el crecimiento de sus exportaciones fue bajo. Esto debido a los manejos del gobierno, el cual estuvo identificado por sus homólogos japoneses como la administración de las tres "k": korupsi, kolupsi y keluarga: corrupción, colusión y familia (Novelo, 1998). En contraparte, la mayor contribución al rápido crecimiento industrial a principios de los años noventa fueron las industrias intensivas en mano de obra como la electrónica, el vestido, textil y calzado, las cuales fueron desprotegidas o contaron con menos atención del gobierno.

Este crecimiento de las exportaciones de las industrias intensivas en mano de obra ocupó el primer lugar, fueron el boom previo a la lenta pero inevitable crisis de 1997, resultado de la debilidad estructural de estas industrias, así como a la emergencia de nuevos competidores en la región, como en los casos del surgimiento de China y Vietnam (Falck, 1998).

En la cuarta etapa (1998-2005), después de la crisis de 1997, el problema estuvo profundamente relacionado con la debilidad estructural de la industria de Indonesia. En este caso, Tambunan (2000) y Kim (2005) señalan que tal situación inhibió la competitividad industrial de Indonesia; la podemos definir en cinco aspectos: escasos productos básicos, mercados y exportaciones; alto índice de importaciones; carencia de atención, conocimiento y dependencia tecnológica industrial; un débil sector de pequeñas y medianas empresas y, finalmente, baja productividad.

A finales del año 2001, el gobierno trató de fortalecer la competitividad por medio de un programa de revitalización consistente en dividir a las industrias en tres categorías, de acuerdo a su nivel y potencial: industrias para ser revitaliza- 
das, para ser desarrolladas y de soporte. La industria para ser revitalizada es aquella con mayor índice de exportación como la textil, la del vestido, del calzado, la electrónica, madera, pulpas y productos de papel. Las industrias para ser desarrolladas tienen alto potencial para absorber mano de obra y ganar en el intercambio al extranjero, incluyendo piel y productos de piel, pesca y procesos de pesca, aceite de palma, fertilizantes, maquinaria agrícola, software y joyería. La industria de soporte es aquélla requerida para fortalecer a la industria de revitalización y de desarrollo, incluyendo la industria de componentes de ingeniería, accesorios y procesos de piel. Sin embargo, el programa se enfocó en general a la creación de empleo a corto plazo y su límite fue hasta 2004, un periodo muy breve y difícil para que en tan corto tiempo el proyecto de revitalización lograra resolver los problemas estructurales que enfrentaba la industria.

\section{Los principales errores de la política industrial de Indonesia}

El problema del desarrollo industrial de Indonesia es complejo, porque se interrelacionan diversas políticas, como la de comercio, el desarrollo tecnológico y competitividad de sus recursos humanos; por separado ninguna podría resolver el problema, ya que se requiere de un trabajo complementario y consistente en cada una de estas áreas para alcanzar sus objetivos de éxito.

La debilidad estructural de la industria de Indonesia es un reflejo de la política que han implementado sus gobiernos. Kim (2005) divide en cuatro áreas los errores de la política anterior.

1. Carencia de una política integral que pretenda desarrollar la política de desarrollo industrial.
2. Errores en el manejo de la estrategia del Estado protector.

3. La falta de estimulación del sector privado en investigación y desarrollo (ID).

4. Falta de promoción del desarrollo de las pymes

Respecto del primer punto, el gobierno ha intervenido en un amplio rango de actividades industriales durante varias décadas, especialistas de la política industrial de Indonesia han argumentado que careció de consistencia y congruencia de largo alcance, puesto que requería de una política que conjuntara esfuerzos de los diferentes sectores relativos a lograrlo, como es la política de comercio, la cual necesita estar integrada con la política industrial, soportada por un sector de recursos humanos capaz de manejar y desarrollar las nuevas tecnologías.

En cuanto al segundo punto, la estrategia del Estado protector consistió en que el gobierno promoviera a las industrias a través de la protección del Estado, y tales sectores debieron producir bienes que contaran con alta tecnología y compitieran con las importaciones de países desarrollados dentro del mercado local. Con este razonamiento, el gobierno escogió diez industrias como estratégicas para promoverlas y apoyarlas extensivamente, pero no consideró que se trataba de industrias que ya eran ineficientes, con problemas de corrupción, todo lo cual se reflejó en un impacto negativo sobre el desarrollo del sector privado.

El tercer punto es la falta de estimulación del sector privado en actividades de investigación y desarrollo. El desarrollo industrial se ubica en el desarrollo de tecnología de empresas privadas. Desde que el gobierno respaldó el desarrollo tecnológico en Indonesia, el soporte financiero del 
gobierno se destinó a la promoción de diez industrias, así como a otras empresas estatales, de tal manera que los fondos para industrias privadas fueron severamente reducidos. En este sentido, los grandes ausentes fueron el estímulo fiscal y la generación de incentivos para la innovación de las empresas privadas. Esto significa que el sector privado en Indonesia no sólo gasta muy poco en capacidad de investigación y desarrollo, sino que aparece como uno de los principales problemas de competitividad.

El cuarto punto se ubica en la falta de promoción y desarrollo de las pymes. Una economía de mercado puede prosperar sólo cuando cuenta con un desarrollo saludable en el sector de las pymes. Las pymes son las mayores proveedoras de empleo, fuentes de innovación y competitividad. No obstante, a pesar de la importancia de las pymes, si el gobierno no nutre

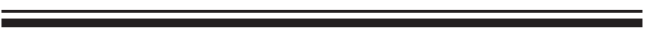

La política del comercio de Indonesia es un dilema por ofrecer una fuerte resistencia interna a la liberalización el comportamiento de las pymes es comparado con las pymes de otras economías en desarrollo. En Indonesia, se denomina como pequeñas empresas a establecimientos que facturan un máximo de 20 millones de rupias, mientras que las empresas medianas facturan de 20 millones hasta 10 billones de rupias. En otras economías el tamaño de las empresas es usualmente definido de acuerdo con el número de trabajadores, información que permite clasificar y comparar más fácilmente una dimensión con otra; de ahí que, por ejemplo, de acuerdo con el Foro de Cooperación Económica Asia-Pacífico (APEC, por sus siglas en inglés), se identifique a Indonesia como una economía con desarrollo bajo. Según las características establecidas por el grupo de trabajo especializado en las pequeñas y medianas empresas, Indonesia es una nación difícil de comparar con las 21 seriamente su desarrollo, se convierten en un tópico político de presión porque involucran diversos problemas difíciles de resolver. Esto precisamente sucedió en Indonesia: el gobierno no puso atención en las pymes para promoverlas y como resultado, el lento crecimiento de las pymes retrasó más el crecimiento de las grandes empresas. El sistema de subcontratación de Indonesia no está bien desarrollado; las pymes principalmente satisfacen al consumidor final, más que suministrar productos a las grandes empresas. Como resultado intra-industrial, este vínculo es extremadamente débil y ello impide el desarrollo de costo-eficiencia local y provisión industrial. economías que participaron en el estudio que se realizó para medir y comparar el estado de las pymes en tres momentos: previo a la crisis de 1997, durante la crisis y después de tal crisis; es decir, analizaron los datos de las pymes de las 21 economías de 1990 hasta el año 2000 (véase cuadro 1). En esta información no fue posible considerar los datos de Indonesia, por la diferencia de definición de tamaños de empresa; descripción que de la misma forma se aprecia según el Banco Mundial (véase en el cuadro 2). Existe, pues, un vacío de información sobre este país, circunstancia que vuelve más difícil establecer un análisis de las pymes de Indonesia. 


\section{Relevancia de las pymes en Indonesia}

Las estrategias para mejorar la dirección de la política industrial de Indonesia se centran precisamente en considerar la relevancia de las pymes, ya que este sector, por su naturaleza, constituye de forma integral una serie de factores mínimos para la política económica de aquel país. Uno de los más importantes cambios es promover la competitividad industrial. De acuerdo con los lineamientos de la Organización Mundial del Comercio, la política industrial no debe contar con la intervención del gobierno en un sentido protector, sino que más bien se pretende un gobierno con un rol de facilitador. En ese sentido, se trata de hacer la economía tan atractiva como sea posible, tanto en el mercado local, principalmente, como en el de inversión extranjera; promover la competencia para la liberalización del comercio, que considere un área de soporte para desarrollar la investigación y el desarrollo, así como el desarrollo del capital humano y especial promoción de las pymes.

La estrategia para mejorar la política industrial de Indonesia consistiría en dos etapas, de corto y de largo plazo. En la primera se trata de medidas inmediatas, con las que se puedan atender los problemas de empleo, una dificultad posible de resolver a través de la inversión extranjera directa en determinados sectores estratégicos, debido a que se trata de un sector que es una fuente de tecnología y formación de capital; mientras que para el largo plazo, la política de inversión consistiría en dotar de recursos e infraestructura al sector privado, el cual se encuentra subdesarrollado. Por lo tanto, es vital un plan de reestructuración corporativa a través del fortalecimiento de sus pymes para vigorizar la base industrial.
Sin embargo, la política del comercio de Indonesia es un dilema por ofrecer una fuerte resistencia interna a la liberalización. Para sobrevivir a la resistencia, el gobierno podría mantener una política complementaria que procure la competitividad internacional de las empresas de Indonesia, proveerlas de incentivos para la inversión, desarrollo de recursos humanos, actividades de investigación y desarrollo. Es decir, un programa de liberalización de importaciones que prepare a las industrias para la competencia exterior - como lo señalan los comités de la OMC, AFTA y APEC-, de tal manera que se puedan eliminar las incertidumbres asociadas a la liberalización del comercio y preparar al sector privado.

La política de desarrollo de las pymes desempeña un rol muy importante en la economía de Indonesia. No obstante, son necesarios esfuerzos intensivos. Tambunan (2005) y Kim (2005) sugieren dirigir dicha política empezando por la identificación de las pymes en este país, debido a que es una definición que cada vez usan más las instituciones internacionales, con el objetivo de ofrecer claridad por medio de una descripción básica que indica el número de trabajadores, de tal manera que se puede comparar, contrastar con otros países, su productividad, índice de exportación y valor agregado, entre otras categorías. En el caso al que nos referimos se trata, primordialmente, del sector manufacturero, en el que las pymes son empresas con un máximo de 200 trabajadores o menos, como se puede apreciar en el cuadro 2.

Por otro lado, considerando la etapa de desarrollo de la economía de Indonesia, la infraestructura institucional es muy débil, pues no cuenta con instituciones financieras, con servicios exclusivos para ellas, las cuales enfrentan gran dificultad 
para asegurar préstamos de los bancos debido a su carencia colateral. El sistema de fondos para garantizar un crédito ayudaría a las pymes a reunir las necesidades financieras. Asimismo, no cuentan con una institución pública responsable de brindar asesoría técnica y administrativa a las pymes. Un centro técnico bajo el control del Ministerio de Industria y Comercio podría ser considerado para subsanar esta carencia.

Además, el sistema de subcontratación debe ser institucionalizado para llevar a cabo la promoción de la subcontratación mediante una ley que especifique para cuáles productos sea posible la subcontratación de las grandes empresas a las medianas, así como a las pequeñas, debido a que son empresas que dependen en gran medida de las importaciones para su producción, desde grandes importaciones de capital y de bienes intermedios hasta materiales procesados en crudo, entre otros productos. Tal situación podría ser deseable para el gobierno: escoger el potencial de sectores ganadores y poner en marcha una política selectiva y de aprovechamiento necesario de las pymes con alto crecimiento o potencial de desarrollo tecnológico y asistencia gubernamental. Finalmente, los esfuerzos debieran enfocarse a estimular la generación de nuevas empresas. Esto es particularmente importante en Indonesia porque el país necesita nuevos empresarios, que puedan encabezar la economía en el futuro. Así habría un número variado de esquemas para promover e iniciar nuevos negocios, los cuales son muy necesarios para el desarrollo de esta nación.

\section{Conclusiones}

De acuerdo con instituciones como el Banco Mundial y el Banco de Desarrollo de Asia, para alcanzar el crecimiento económico de los países en desarrollo, es urgente — según la revisión que se hizo de las cuatro etapas de la política industrial de Indonesia, así como de los principales errores que se han cometido en la conducción de dicha política - trabajar en el desarrollo de las pymes, pues en este caso se presentan como el centro de la problemática de la política industrial.

Como se señaló anteriormente, las pymes de Indonesia demandan una conducción interdisciplinaria para destacar en el entorno competitivo internacional, que considere una política que oriente programas y acciones para el fomento de estas entidades productivas, ya que todavía se encuentra en una de las etapas iniciales de desarrollo industrial y, por lo mismo, han sido víctimas de la débil política industrial de este país; sin embargo, promover el crecimiento de las pymes ayudaría a resolver las fallas específicas de todas las empresas, independientemente del tamaño.

\section{Cuadro 1 \\ Clasificación de pequeñas y medianas empresas en Indonesia. 1996}

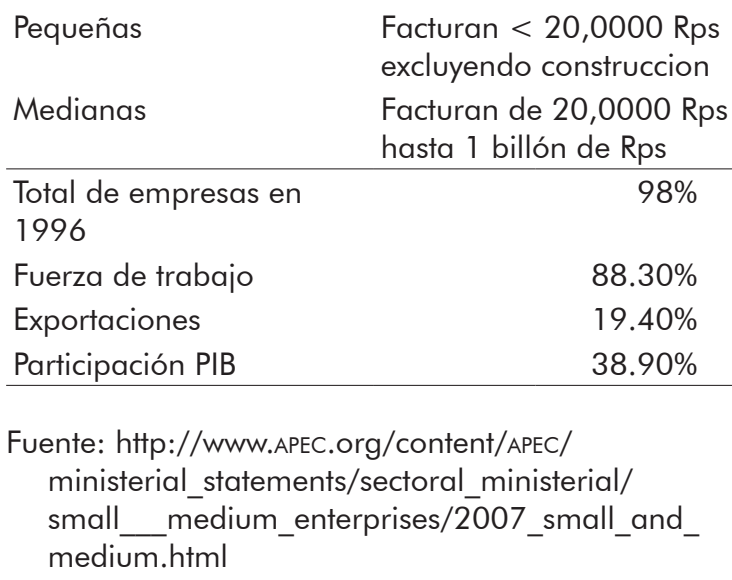

MÉXICO YLACUENCADEL PACÍFICO vol. 10, núm. 29 / mayo - agosto de 2007 


\section{Análisis}

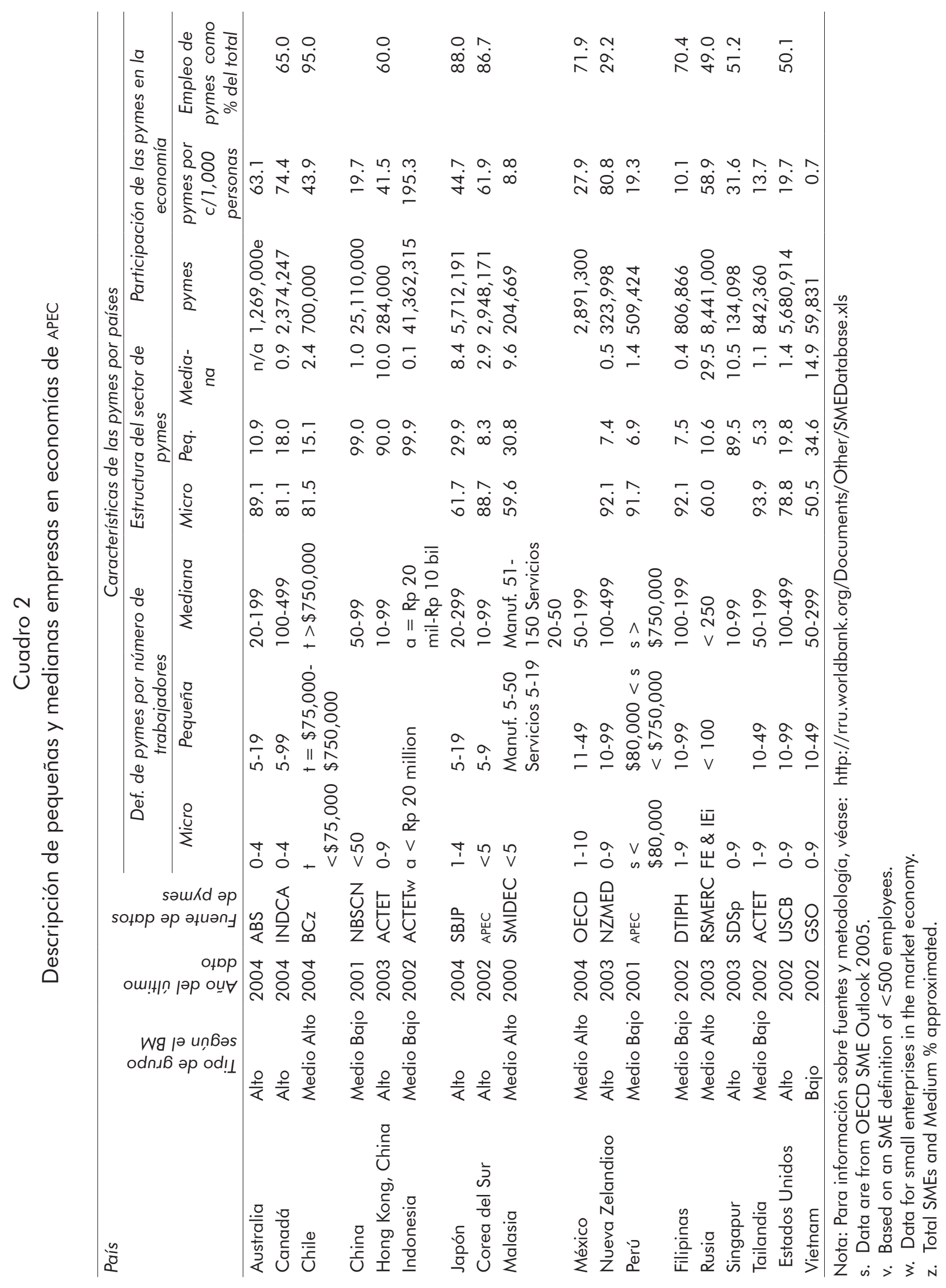

24 MÉXICO YLACUENCADEL PACÍFICO

vol. 10, núm. 29 / mayo-agosto de 2007 


\section{Bibliografía}

Corona, Treviño Leonel, Pequeña y mediana empresa: del diagnóstico a las políticas, UNAM, México, 1997.

Falck, Melba, "Indonesia: ¿̇al borde del abismo?", México y la Cuenca del Pacífico, vol. 1, núm. 2, Universidad de Guadalajara, México, 1998, pp. 3-6.

Hooley, Richard y Muzaffer Ahmad (2003) The Role of Small and Medium-Scale Manufacturing Industries in Industrial Development: The Experience of Select Asian Countries, Asian Development Bank Publication, Economic and Development Bank Publication, Economic and Development Resource Center, Manila, Filipinas, pp. 423.

Http://www.APEC.org/content/APEC/publications/ all publications/small medium enterprises.html. 1998. Profile of SME in the APEC Economies. Fecha de registro $1^{\circ}$ de mayo de 2007.

Http://www.APEC.org/content/APEC/ministerial statements/sectoral ministerial/small medium enterprises/2007_small_and_medium.html. Fecha de registro: $1^{\circ}$ mayo de 2007 .

Http://rru.worldbank.org/Documents/Other/SMEDatabase.xls. Fecha de registro: 7 de febrero de 2006.

Indonesian Business Intelligence Report, 2005, pp. 10-36.
Kim, Chuk Kyo, "An Industrial Development Strategy for Indonesia: Lessons from South Korean Experience", Journal of the Asia Pacific Economy, vol. 10, núm. 3, Routledge, 2005, pp. 312-338.

Moncada García, Dulce Ma., Anuario Asia Pacífico 2005, El Colegio de México, México, 2005, pp. 162-163.

Novelo, Silvia, "El colapso de Indonesia visto desde Japón", México y la Cuenca del Pacífico, vol. 1, núm. 2, Universidad de Guadalajara, 1998, pp. 7-8.

Santa Cruz, Arturo, "Indonesia: ¿̇el precio del autoritarismo?", México y la Cuenca del Pacífico, vol. 1, núm. 2, Universidad de Guadalajara, 1998, pp. 1-3.

"La larga transición en Indonesia", México y la Cuenca del Pacífico, vol. 4, núm. 13, Universidad de Guadalajara, 2001, pp. 71-73.

Tambunan, Tulus, "The Performance of Small Enterprises during Economic Crisis Evidence from Indonesia", Journal of Small Business Management, vol. 38, núm. 4, ABI/INFORM Global, 2000, pp. 93-101.

, "Promoting Small and Medium Enterprises with a Clustering Approach: A Policy Experience from Indonesia", Journal of Small Business Management, vol. 43, núm. 2, ABI/INFORM Global, 2005, pp. 138-154. 